\title{
A Review on the Treatment of Osteoporosis with Equisetum arvense
}

\section{Gabriele Saudelli ${ }^{1^{*}}$, Laura Tinti ${ }^{2}$ and Giovanni Suffritti ${ }^{3}$}

${ }^{1}$ Faculty of Medicine and Surgery, Department of Chinese Acupuncture, Phytotherapy, Traditional Chinese Medicine and Integrated Medicine, University of Siena, Italy

${ }^{2}$ Department of Chemistry and Pharmaceutical Technologies, University of Siena, Italy

${ }^{3}$ Research and Development of Ghimas, Casalecchio di Reno - Bologna, Italy

*Corresponding author: Gabriele Saudelli, Faculty of Medicine and Surgery, Department of Chinese Acupuncture, Phytotherapy, Traditional Chinese Medicine and Integrated Medicine, University of Siena, Italy, Tel: + 886-2-28757296; E-mail: giovanni.suffritti@ghimas.it

Rec date: April 04, 2018; Acc date: April 24, 2018; Pub date: May 1, 2018

Copyright: ( 2018 Saudelli G, et al. this is an open-access article distributed under the terms of the Creative Commons Attribution License, which permits unrestricted use, distribution, and reproduction in any medium, provided the original author and source are credited.

\begin{abstract}
Background: The present review aims to verify in osteoporosis the effectiveness of the silicon diet, contained in the Equisetum arvense.

What is documented in the literature makes it possible to conclude that silicon improves the formation, consistency and density of bone tissue and cartilage tissue, and excites osteosynthesis through an enhanced biosynthesis of collagen.

Treatment with Osteosil Calcium (a silicon-based food supplement extracted from Equisetum arvense and calcium) induces an increase in plasma and tissue silicon concentrations, the greater availability of which results in an increase in the activity of all silicon enzymatic reactions. This is the case of the enzyme prolyl-hydroxylase, which intervenes in the early stages of the synthesis of collagen at the ribosomal level of fibroblasts of connective tissue. Silicon plays a decisive role in normalizing the content of glycosaminoglycans in collagen, which in turn is used as a matrix for the formation of both cartilage and bone.

Osteosil Calcium is effective in osteoporosis because silicon, present in the product, acts from the early stages of bone and cartilage formation. The silicon contained in Osteosil Calcium, "exciting" the physiological mechanisms used to produce collagen and glycosaminoglycans, improves in an objective way the pathological states of the bone (osteoporosis, arthritic or post-traumatic bone degeneration, bone fracture, orthopaedic and dental surgery, and guided bone regeneration): in fact, silicon promotes and activates, qualitatively and quantitatively, the bone remodeling processes.
\end{abstract}

Keywords Equisetum arvense; Osteoporosis; Nordin test; Bone densitometry

\section{Introduction}

Osteoporosis is characterized by a progressive quantitative reduction of bone mass, without modification of the ratio between organic component and mineral component [1]. It is surely the most frequent bone disease, in relation to the prolonged life expectancy of the population [2]. Osteoporosis depends on many factors (Figure 1):

- Reduction of gonadal function, with bone loss affecting the trabecular part more than the cortical area, with frequent vertebral fractures and distal end of the radio [3-5] with remarkable speed bone loss and reduction of parathyroid function and calcium absorption [6-8];

- Poor calcium diet [6];

- Excessive sodium intake [9];

- Sedentary life [10];

- High and prolonged intake of alcohol and coffee [11,12];

- Cigarette smoking [13].

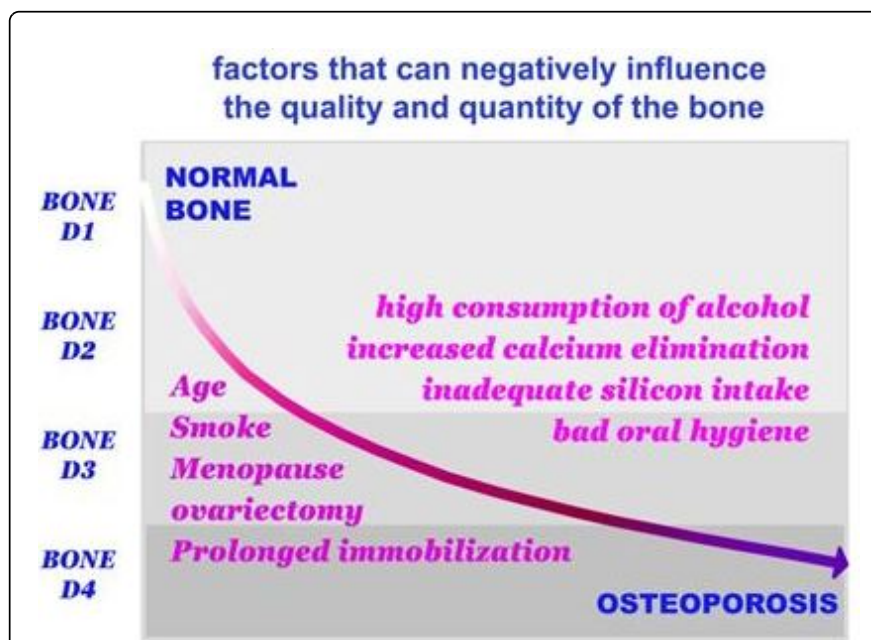

Figure 1: Factors that can negatively influence the quality and quantity of the bone. 


\section{Literature Review}

Female sex is much more affected than male (with a ratio of 6:1), especially in relation to the decrease in estroprogestinic production typical of menopause $[7,8]$.

The work signed by Silvio Garattini, published on the monthly magazine of the Mario Negri Institute for Pharmacological Research "Menopause: The Risks of Hormone Replacement Therapy", while reiterating the positive effect of hormone therapy on osteoporosis and the troublesome vasomotor symptoms, recalls the attention to the effects of prolonged oestrogen therapy that results in significant risk increase in breast cancer and severe cardiovascular damage [14]. By making the algebraic sum of the risks and benefits, concludes the founder of the Mario Negri Institute, for each year of treatment there are 19 serious additional events per 10.000 treated women.

For a 10-year treatment, this corresponds to $190 / 10.000$, or about $2 \%$ of women experience a serious event. Considering that there are tens of millions of women being treated in Europe, the number of serious adverse events becomes very significant. All this entails for the physician a careful assessment of the risks and benefits of hormone therapy and urges him to re-evaluate possible alternatives to drug treatments that are equally relevant to the symptoms of postmenopausal osteoporosis.

Equisetum arvense is said in the traditional East Asian medicine $\mathrm{Mu}$ Zei and is believed to be a vital ingredient in the formation of bone and cartilage tissue. As such, Equisetum arvense is still recommended by some oriental doctors to help strengthen the bone and prevent the onset of osteoporosis and is also used in the treatment of some neoplastic forms [15]. It is also described as an ingredient of an herbal formula against HPV, the Papilloma virus. Recent acquisitions on the implications of silicon in bone metabolism and its role in determining the formation and properties of collagen, and consequently cartilage and bone tissue, indicate its possible pathogenetic participation in the decreased availability of silicon within the degenerative osteoarticular processes and as a consequence hypothesize that the use of silicon complementation can be both preventative and curative treatment of osteoarthritis and osteoporosis [16-25].

The role of silicon as an "essential mineral" in the formation and characteristics of collagen has been extensively demonstrated [26-28]. At the molecular level, it was possible to highlight its implication in the synthesis of mucopolysaccharides of articular cartilage and connective tissues.

Mucopolysaccharides are also determinant in bone mineralization (ossification starts in fact in the calcification areas with polysaccharide nuclei); the activity of proline-hydroxylase, an enzyme responsible for the synthesis of bone and cartilage collagen, present in the osteoblasts, chondroblasts and fibroblasts microsomes, is silicon-dependent (silicon deficiency is associated with a low content in glycosaminoglycans of collagen) [29]. In bone mineralization sites, $\mathrm{Ca} / \mathrm{Si}$ ratio dependent silicon concentrations are high in the initial stages of the calcification process $(\mathrm{Ca} / \mathrm{Si}=0.7)$ and very low in the final stages $(\mathrm{Ca} / \mathrm{Si}=1.7)$. It has also been shown that bone mineralization is directly proportional to the silicon content of the diet. These assumptions are the basis of the action of an intake silicon diet, contained in the Equisetum arvense (rich in silicon in the form of orthosilic acid), whose dry titrated extract is the active ingredient of the dietary/therapeutic product OSTEOSIL Calcium ${ }^{\circ}$ (Ghimas SpA, Casalecchio di Reno-Bologna, Italy) also containing, at the indicated dose, one third of the daily calcium dose recommended by the WHO.
Since 1960, Carlisle demonstrated that silicon plays a key role in bone calcification mechanisms in chick and rat, highlighting both the correlations between diet silicon content, collagen biosynthesis and bone mineralization, as well as close relationships between silicon and calcium in ossification processes [30-35]. Subsequent scientific papers confirmed these data $[17,19,28,36]$.

These experimental trials also indicate that silicon plays a crucial role in normalizing the glycosaminoglycan content in collagen. The collagen thus formed is itself used as a matrix for the formation of the connective tissue of cartilage and bone. As confirmation of the indispensable action of silicon, the early stages of collagen synthesis are conditioned by the activity of the prolyl-hydroxylase enzyme, which is silicon-dependent $[27,30,37]$. Its presence, therefore, ensures a normal and physiological synthesis of both cartilage and bone tissue.

Equisetum arvense, in addition to its catalytic activity on prolylhydroxylase enzyme, seems to have a negative effect on human osteoclastogenesis, which is in line with its alleged beneficial role in pathophysiological conditions associated with greater osteoclastic activity and may suggest a potential useful for treatment with bone regeneration strategies [35].

This information has found experimental confirmation in a controlled study that describes the effects of dry extract of Equisetum arvense, which contains a special form of oral silicon active on the growth of teeth and bones long in the rat: the addition to the normal diet of titrated extract of Equisetum arvense (active component of Osteosil Calcium) has resulted in a marked improvement both in length and length of bones, with greater bone density and compactness [38].

\section{Discussion}

In the 1990s it was confirmed the mineralizing action in the prevention and treatment of osteoporosis, together with improvements in joint pain that accompany osteoporosis in all the treated patients [30,40]. Gründemann et al. [41] indicate, however, that the extract of Equisetum arvense interferes with the poly-functionality of immunecompetent cells, thus providing an anti-inflammatory mode-of-action. $\mathrm{T}$ cell proliferation, in fact, was inhibited dose dependently by Equisetum without induction of apoptosis or necrosis. This effect was mediated by inhibition of lymphocyte activation, specifically by diminishing CD69 and IL-2 surface receptor expression and intracellular IL-2 production. Furthermore, treatment with Equisetum arvense inhibited effector functions, as indicated by reduced production of IFN- $\gamma$ and TNF- $\alpha$.

The study by Mattioli-Belmonte et al. [42] documented the efficacy of Osteosil Calcium in vitro in improving the vitality and metabolic function of osteoblasts.

The morphological SEM evaluation of the culture of an osteoblastic MG63 cell line showed as with a $2.5 \mu \mathrm{g} / \mathrm{ml}$ concentration of Osteosil Calcium, cells form a "carpet" diffused across the culture plate.

At the $5 \mu \mathrm{g} / \mathrm{ml}$ concentration of Osteosil Calcium this carpet appears more homogeneous with greater adhesion to the substrate. In cell cultures treated with $10 \mu \mathrm{g} / \mathrm{ml}$ concentration of Osteosil Calcium, cellular morphology expresses a state of correct metabolic activity (good anchorage to the substrate, no apparent degenerative necrotic aspects). Blood concentrations of between 2.5 to $10 \mu \mathrm{g} / \mathrm{ml}$, achieved by the recommended dosage of Osteosil Calcium, are therefore the optimal treatment for a balanced supply of silicon and calcium even for 
Page 3 of 5

prolonged administration periods. The EDAX micro-analytical analysis confirms that silicon and calcium administered with Osteosil Calcium are utilized by osteoblasts in their metabolism for bone production. Bessa Pereira et al. [24] confirmed these data.

The graduation thesis of Laura Tinti [43] discussed with prof. Gabriele Saudelli, $2^{\text {nd }}$ level Master in Phytotherapy, University of Siena (Italy), attempted to quantify the effective dose to obtain bone and cartilage growth by measuring nitric oxide (NO), such as oxidative stress capable of inhibiting the regrowth of chondrocytes and osteoblasts in human cells grown in vitro. The study evaluated whether the amount of NO released by chondrocytes stimulated with proinflammatory cytokine IL $1 \beta$ exogenous could be reduced by treatment with Equisetum arvense, since experiments conducted in vitro have proved its action as a scavenger of free radicals, including also NO [44-46]. In the cells that underwent IL1 $\beta$ stimulation, a decrease in the NO levels induced by the pro-inflammatory cytokine was observed at both Equisetum arvense concentrations tested $(200 \mu \mathrm{g} / \mathrm{ml}$ and $100 \mu \mathrm{g} /$ $\mathrm{ml}$ ), despite the concentration $100 \mu \mathrm{g} / \mathrm{ml}$ is more effective, reporting the amount of NO released at baseline levels (Figure 2).

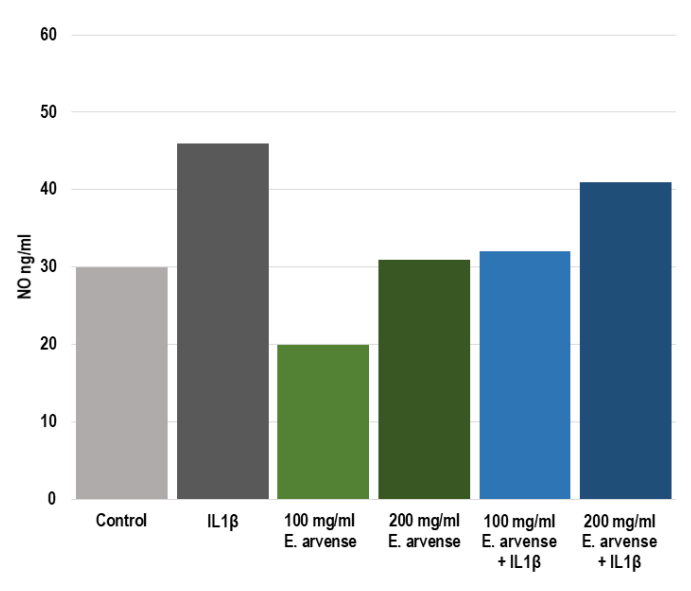

Figure 2: Quantification of the nitroxide released by chondrocytes treated with various concentrations of hydroalcoholic extract of Equisetum arvense $(200 \mu \mathrm{g} / \mathrm{ml}$ and $100 \mu \mathrm{g} / \mathrm{ml})$ with and without addition of IL1 $\beta(1 \mathrm{ng} / \mathrm{ml})$.

For a more complete view of the mechanism of action underlying the reduction of NO levels released by chondrocytes, the gene expression of iNOS (Nitric Oxide Synthase Inhibitor) was investigated. After analysis of the data obtained from the cell viability assay and the Griess assay, we decided to exclude from the analysis the treatment at the concentration of $400 \mu \mathrm{g} / \mathrm{ml}$, which showed cytotoxicity, and the treatment with Equisetum arvense powder that showed an increase of NO released compared to chondrocytes in baseline conditions.

After a careful analysis of the data obtained from the quantification of NO release by chondrocytes stimulated with the pro-inflammatory cytokine IL1 $\beta$ and pre-treated with hydroalcoholic extract of Equisetum arvense, we can conclude that the concentration $100 \mu \mathrm{g} / \mathrm{ml}$ showed a good efficacy in counteracting the increase in NO levels induced by the cytokine IL1 $\beta$.

In support of the data obtained from the Griess assay we have obtained encouraging results regarding the gene expression of the enzyme responsible for the release of NO at high levels i.e., iNOS. The gene expression of this enzyme is overexpressed in chondrocytes stimulated with IL1 $\beta$ (also from literature data); this condition can be counteracted by treatment with Equisetum arvense.

Therefore, although further studies are necessary, we can conclude that the Equisetum arvense in addition to stimulating the enzyme prolyl hydroxylase with its high silicon content, which increases the production of collagen and glycosaminoglycans, may have another beneficial effect on osteoarticular disease, reducing precisely the synthesis and release of nitric oxide by osteoarticular chondrocytes, leading to an improvement of the disease.

The study by Corletto [47] showed that treatment with Osteosil Calcium was well tolerated by all patients observed and confirmed active on calcium loss rate after 40 days of therapy, bringing this phenomenon to values close to those considered normal for the age range of patients considered.

This datum assumes great importance since only fast-loser patients were admitted to the study, showing a loss of calcium higher than $2.7 \%$ per annum at the Nordin test.

The variation of the patients treated with Equisetum e.s.t. indicates a marked improvement in control after 40 days $(\mathrm{P}<0.001)$, which increases slightly to the final control. In patients treated first with Placebo, then with Equisetum e.s.t. a significantly positive decrease was observed only at the control after 80 days $(\mathrm{P}<0.001)$, while in the first treatment period no changes were noted. There are no notable changes in the control patients who took placebo.

Patients treated with Osteosil Calcium showed a marked improvement in control after 40 days $(\mathrm{P}<0.001)$, which increased further to the final control $(\mathrm{P}<0.05)$ (Figure 3$)$.

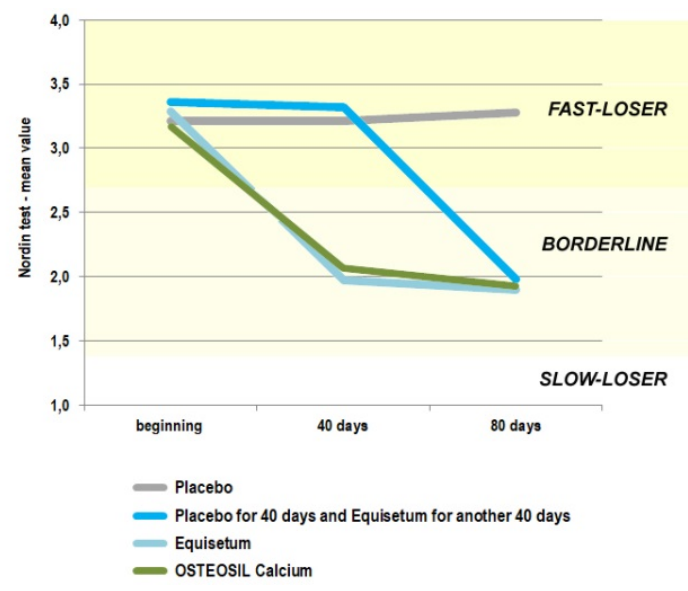

Figure 3: Graphic representation of variation of the Nordin test.

The variations of the Nordin test therefore indicate that Placebo treatment is not active; instead, the subsequent administration of Equisetum e.s.t. patients initially treated with Placebo induced the same changes observed in the group of subjects treated with the active substance; treatment with Equisetum e.s.t. and with Osteosil Calcium has transformed all fast-loser patients into borderline patients, reducing calcium loss and thus improving bone metabolism.

Total body bone densitometry also shows, in the year of observation, a significant bone mass recovery (approximately 2.3\%) at 
Page 4 of 5

the vertebral level; in untreated patients, however, the decrease in bone density has continued steadily (Figure 4 ).

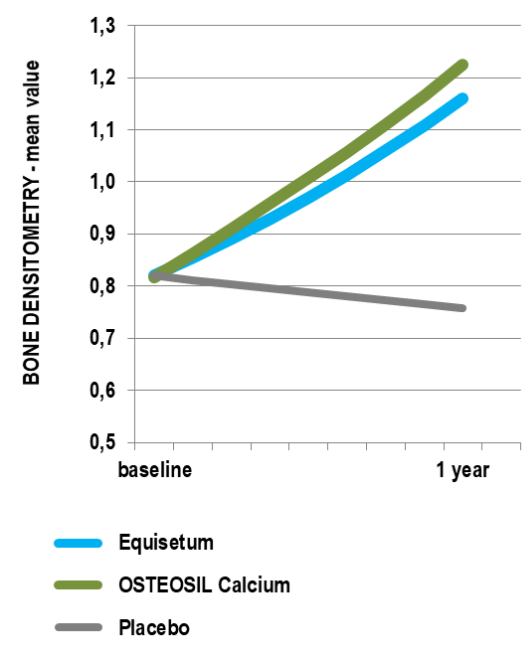

Figure 4: Graphic representation of the variation of the total body bone densitometry. Compared to untreated fast-loser controls (placebo), which tend to decrease bone density, Osteosil Calcium and Equisetum after a year of therapy induce an increase in bone mass at vertebral level of $2.3 \%$.

The most frequent and easiest to find objectively from a clinical point of view, as in the previous study, was the decrease in osteoarthritic pain. The increase in bone density is confirmed by the improvement of the Nordin test, which demonstrates the reduction of osteoclastic activity and the positive increase in osteoblastic activity.

We report the following Case report that is truly emblematic: A 70year-old patient was observed for osteoporosis with T-Score of -3.30 at the computerized bone mineralometry performed on the L2-L4 lumbar spine. Treatment with Osteosil Calcium is started at the dosage of two tablets a day, taken daily for one year until the next densitometry. This was done with the same device used previously. The result is -1.8 (same lumbar segment). Two years later the densitometry was repeated (same machine, same operator), this time by total body technique. The T-score was further raised up to -0.7. Throughout this period, treatment with Osteosil Calcium continued, continuing with the daily dose of two tablets taken during the main meal.

In the course of osteoporosis, the fall of the blood silicon is earlier and more pronounced than that of other minerals (calcium, phosphorus, fluorine and magnesium) involved in the calcification process of the bones $[5,29]$. The high content of silicon in Osteosil Calcium seems therefore to be the main cause of therapeutic action, which has transformed all of the fast-loser patients in borderline patients.

It should be emphasized, however, that the best trend in Osteosil Calcium treated patients indicates that supplementation of calcium therapy in WHO recommended doses is undoubtedly a better condition for bone metabolism, with a more effective bone mass increase. The calcium intake through Osteosil Calcium, in fact, proves to be able to supplement the calcium intake normally taken with the diet, thus optimizing the action of Equisetum arvense.
This leads to the conclusion that silicon in Osteosil Calcium improves the formation, consistency and density of bone tissue and cartilage tissue, stimulating osteosynthesis through enhanced collagen biosynthesis [47-50]. The treatment with Osteosil Calcium induces an increase in plasma and tissue concentrations of silicon, whose increased availability translates into an increase in the activity of all silicon-dependent enzymatic reactions. This is the case of the enzyme prolyl-hydroxylase, which intervenes just in the early stages of collagen synthesis at the level of ribosomal connective tissue fibroblasts. Silicon plays a decisive role in normalizing the glycosaminoglycan content in collagen, collagen that is in turn used as a matrix for the formation of both cartilage and bone $[27,37,51,52]$.

\section{Conclusion}

Osteosil Calcium can therefore be used to treat osteoporosis without side effects at doses of 2 tablets/day for 45 days followed by 15 days of suspension for 3-4 cycles per year. Silicon, present in the product, is effective in osteoporosis because it acts since the early stages of bone and cartilage formation. Silicon, "exciting" the physiological mechanisms involved in the production of collagen and glycosaminoglycans, objectively improves bone pathologies (osteoporosis, osteoarthritis or post-traumatic bone degeneration, bone fracture, orthopaedic and dental surgery, and guided bone regeneration): silicon, in fact, promotes and activates, qualitatively and quantitatively, bone remodeling processes.

\section{Conflicts of Interest}

The authors declare no conflicts of interest related to this study.

\section{References}

1. Consensus Development Conference (1991) Prophylaxis and treatment of osteoporosis. Am J Med 90: 107-110.

2. Stevenson JC (1988) Osteoporosis: Pathogenesis and risk factors. Baillieres Clin Endocrinol Metab 2: 87-101.

3. Riggs BL, Melton LJ (1990) Clinical heterogeneity of involutional osteoporosis: Implications for preventive therapy. J Clin Endocrinol Metab 70: 1229-1232.

4. Jackson RD, Mazzaferri EL (1997) Forestalling fracture in osteoporosis: Case commentary. Hosp Pract 32: 77-108.

5. Auquier P, Manuel C, Molines C (1997) Risk factors for post-menopausal osteoporosis. Review of the literature 1990-1995. Rev Epidemiol Sante Publique 45: 328-342.

6. Rec Lab RR (1978) Menopausal changes in bone remodeling. J Lab Clin Med 92: 964-970.

7. Gasbarrini G, Armor GR, Di Sario A (1992) Osteoporosis for the practical doctor.

8. MacLennan A (1997) Osteoporosis: Menopause and beyond. Australian family physician 26: 123-125.

9. Breslau NA, Mcguire JL, Zerwekh JE, Pak CY (1982) The role of dietary sodium on renal excretion and intestinal absorption of calcium and on vitamin D metabolism. J Clin Endocrinol Metab 55: 369-373.

10. Anonymous (1983) Immobilization and bone. Calcif Tissue Int 35: 265-267.

11. Spencer H, Rubio N, Rubio E (1986) Chronic alcoholism. Frequently over-looked cause of osteoporosis in men. Am J Med 80: 393-397.

12. Heaney RP (1987) The role of nutrition in prevention and management of osteoporosis. Clin Obstet Gynecol 50: 833-846.

13. Jensen J, Christiansen C, Rødbro P (1985) Cigarette smoking, serum estrogens and bone loss during hormone-replacement therapy early after menopause. N Engl J Med 313: 973-975. 
Page 5 of 5

14. Neri A, Fabris S, Agnelli L (2003) Integrated genomic approach for the molecular classification of multiple myeloma. nanomedicine: From nanostructures to personalized therapy. Negri New 1: 121.

15. Li H, Wang P, Liu Q, Cheng X, Zhou Y, et al. (2012) Cell cycle arrest and cell apoptosis induced by Equisetum hyemale extract in murine leukemia L1210 cells. Ethnopharmacol 144: 322-327.

16. Monceaux RH (1960) Silicon: Biological and pharmacological study. Prod Pharm 15: 99.

17. Eisinger J, Clairet D (1993) Effects of silicon, fluoride, etidronate and magnesium on bone mineral density: A retrospective study. Magnesium Research 6: 247-249.

18. Hott M, De Pollak C, Modrowski D, Marie PJ (1993) Short-term effects of organic silicon on trabecular bone in mature ovariectomized rats. Calcif Tissue Int 53: 174-179.

19. Seaborn CD, Nielsen FH (1994) Effects of germanium and silicon on bone mineralization. Biol Trace Elem Res 42:151-164.

20. Kitsugi T, Nakamura T, Oka M, Cho SB, Miyaji F, et al. (1995) Bonebonding behavior of three heat-treated silica gels implanted in mature rabbit bone. Calcif Tissue Int 57: 155-160.

21. Chapuy MC, Meunier PJ (1995) Prevention and treatment of osteoporosis. Aging (Milano) 7: 164-173.

22. Li P, Ye X, Kangasniemi I, De Blieck-Hogervorst JM, Klein CP, et al (1995) In vivo calcium phosphate formation induced by sol-gel-prepared silica. J Biomed Mater Res A 29: 325-328.

23. Costa RJ, Carmo SC, Silva JC, Fernandes MH (2012) Inhibition of human in vitro osteoclastogenesis by Equisetum arvense. Cell Prolif 45: 566-576.

24. Bessa Pereira C, Gomes PS, Costa-Rodrigues J, Almeida Palmas R, Vieira L, et al. (2012) Equisetum arvense hydromethanolic extracts in bone tissue regeneration: In vitro osteoblastic modulation and antibacterial activity. Cell Prolif 45: 386-396.

25. Kotwal SD, Badole SR (2016) Anabolic therapy with Equisetum arvense along with bone mineralising nutrients in ovariectomized rat model of osteoporosis. Indian J Pharmacol 48: 312-315.

26. Carlisle EM (1974) Proceedings: Silicon as an essential element. Fed Proc 33: $1758-1766$.

27. Mancinella A (1991) Silicon, a trace element essential for living organisms. Recent knowledge on its preventive role in atherosclerotic process, aging and neoplasms. Clin Ter 137: 343-350.

28. Elliot MA, Edwards HM Jr (1991) Effect of dietary silicon on growth and skeletal development in chickens. J Nutr 121: 201-207.

29. Carlisle EM (1975) Silicon in the osteoblast, the bone forming cell. Fed Proc 34: 972

30. Carlisle EM (1970) A relationship between silicon and calcium in bone formation. Fed Proc 29; 265.

31. Carlisle EM (1970) Silicon: A possible factor in bone calcification. Science 167: 279-280.

32. Carlisle EM (1972) Silicon: An essential element for the chick. Science 178: 619-621.

33. Carlisle EM (1976) In vivo requirement for silicon in articular cartilage and connective tissue formation in the chick. J Nutr 106: 478-484.

34. Carlisle EM, Alpenfels WF (1980) A silicon requirement for normal growth of cartilage in culture. Fed Proc 39: 787.

35. Carlisle EM, Berger JW, Alpenfels WF (1981) Silicon: A requirement for prolyl-hydroxylase activity. Fed Proc 40: 366
36. Keeting PE, Oursler MJ, Wiegand KE, Bonde SK, Spelsberg TC, et al. (1992) Zeolite, a increase proliferation, differentiation and transforming growth factor beta production in normal adult human osteoblast-like cells in vitro. J Bone Miner Res 7: 1281-1289.

37. Absher M, Sylwester D (1981) Effects of silica on human lung fibroblasts: Survival data analysis of time-lapse cinematography data. Environ Res 26 : 438-452.

38. Betti V (1990) Effects of the dry extract titled Equisetum arvense on the growth of teeth and long bones in the rat. Dental Current Suppl 7: 1.

39. Finzi M, Raggi R (1991) Equisetum arvense in the degenerative pathology of the osteo-articular system. H Hosp Manag supp 97: 1.

40. Dragos D, Gilca M, Gaman L, Vlad A, Iosif L, et al. (2017) Phytomedicine in joint disorders. Nutrients 9: 70.

41. Gründemann C, Lengen K, Sauer B, Garcia-Käufer M, Zehl M, et al. (2014) Equisetum arvense (common horsetail) modulates the function of inflammatory immunecompetent cells. BMC Complement Altern Med 14: 283.

42. Mattioli-Belmonte M, Kyriakidou K, Lucarini G, Gorrieri O, Giavaresi G, et al. (2005) Cell dynamics in the correct control of bone metabolism using natural treatments. Int J Artif Organs 28: 1259-1271.

43. Tinti L (2009) Role of the Equisetum arvense in the treatment of osteoarticular pathology. master's thesis in phytotherapy, university of siena.

44. Ryu JH, Ahn H, Kim JY, Kim YK (2003) Inhibitory activity of plant extracts on nitric oxide synthesis in LPS-activated macrophages. Phytother Res 17: 485-489.

45. Stajner D, Popović BM, Canadanović-Brunet J, Boza P (2006) Free radical scavenging activity of three Equisetum species from fruska gora mountain. Fitoterapia 77: 601-604.

46. Mimica-Dukic N, Simin N, Cvejic J, Jovin E, Orcic D, et al. (2008) Phenolic compounds in field horsetail (Equisetum arvense L.) as natural antioxidants. Molecules 13:1455-1464.

47. Price CT, Koval KJ, Langford JR (2013) Silicon: A review of its potential role in the prevention and treatment of postmenopausal osteoporosis. Int J Endocrinol 2013: 316783

48. Jugdaohsingh R, Tucker KL, Qiao N, Cupples LA, Kiel DP, et al. (2004) Dietary silicon intake is positively associated with bone mineral density in men and premenopausal women of the framingham offspring cohort. J Bone Miner Res 19: 297-307.

49. Macdonald HM, Hardcastle AC, Jugdaohsingh R, Fraser WD, Reid DM, et al. (2012) Dietary silicon interacts with oestrogen to influence bone health: Evidence from the aberdeen prospective osteoporosis screening study. Bone 50: 681-687.

50. Rodella LF, Bonazza V, Labanca M, Lonati C, Rezzani R (2014) A review of the effects of dietary silicon intake on bone homeostasis and regeneration. J Nutr Health Aging 18: 820-826.

51. Reffitt DM, Ogston N, Jugdaohsingh R, Cheung HF, Evans BA, et al. (2003) Orthosilicic acid stimulates collagen type 1 synthesis and osteoblastic differentiation in human osteoblast-like cells in vitro. Bone 32: $127-135$

52. Dong M, Jiao G, Liu H, Wu W, Li S, et al. (2016) Biological silicon stimulates collagen type 1 and osteocalcin synthesis in human osteoblastlike cells through the BMP-2/Smad/RUNX2 signaling pathway. Biol Trace Elem Res 173: 306-315. 